\title{
Study on the efficiency of advanced pressing in the Premier League
}

Authors' Contribution: A Study Design B Data Collection C Statistical Analysis D Data Interpretation E Manuscript Preparation F Literature Search G Funds Collection

\section{Sorin Brîndescu ACDG, Francisc-Remus Datcu CDFG, lonut-Alexadru Buda BEFG}

Faculty of Physical Education and Sport, West University of Timisoara, Timisoara, Romania

\section{abstract}

Background: Advanced pressing is a tactical relationship which consists of a joint effort which players undertake to win back possession as high up the pitch as possible. It comes as a direct counter to slow build-up styles like the tiki-taka and has existed, historically, for decades. The best examples from history can be Ajax and Feyenoord in the 1970s, as well as the Dutch national team from the same period. In these days, some of English teams use this tactical relationship with the desire to recover the ball as quickly as possible.

Material and methods:

In order to analyze the efficiency of advanced pressing in modern football, we have used statistical analysis which we took from the site fbref.com [accessed on 20 April, 2021], key raw pressing statistics like \% of successful pressing attempts, as well as viewing football games to see which teams use a high, medium or low defensive block. We have analyzed how far up the pitch they usually defend and press, how successful they are with their pressing and what their dependencies are.

Results: On average, although there is a dependency on the quality of the players available in the squad, teams which adopted an advanced pressing tactic had better results than teams which did not. They won the ball higher up the field and initiated goal actions much closer to the opposition's goal.

Conclusions: In modern football, teams which use advanced pressing have better results than teams who prefer to sit deep and let the opposition build from the back. Advanced pressing produces good results for other attacking statistics as well: entries in the final third, expected goals and overall league position, but it is not the only success factor. Teams still need to be capable of holding their defensive shape in order to avoid having large gaps between their defenders and their attackers.

Key words: advanced pressing, tactics, football.

\section{article details}

Article statistics: Word count: 2,470; Tables: 4; Figures: 1; References: 28

Received: June 2021; Accepted: October 2021; Published: November 2021

Full-text PDF: http://www.balticsportscience.com

Copyright @ Gdansk University of Physical Education and Sport, Poland

Indexation: Celdes, Clarivate Analytics Emerging Sources Citation Index (ESCI), CNKI Scholar (China National Knowledge Infrastructure), CNPIEC, DOAJ, EBSCO - Central \& Eastern European Academic Source, EBSCO - SPORTDiscus, EBSCO Discovery Service, Google Scholar, Index Copernicus, J-Gate, Naviga (Softweco, Primo Central (ExLibris), ProQuest - Family Health, ProQuest - Health \& Medical Complete, ProQuest - Illustrata: Health Sciences, ProQuest Nursing \& Allied Health Source, Summon (Serials Solutions/ProQuest, TDOne (TDNet), Ulrich's Periodicals Directory/ ulrichsweb, WorldCat (OCLC)

Funding: This research received no specific grant from any funding agency in the public, commercial, or not-for-profit sectors.

Conflict of interests: Authors have declared that no competing interest exists.

Corresponding author: Sorin Brîndescu; Faculty of Physical Education and Sport, West University of Timisoara; email: sorin.brindescu@ e-uvt.ro

Open Access License: This is an open access article distributed under the terms of the Creative Commons Attribution-Non-Commercial-NoDerivatives 4.0 International (https://creativecommons.org/licenses/by-nc-nd/4.0/), which permits use, distribution, and reproduction in any medium, provided the original work is properly cited, the use is non-commercial and is otherwise in compliance with the license. 


\section{INTRODUCTION}

Intensive progress in technologies for position tracking has enabled acquisition of high quality data describing the movements of players in sport games, in particular, football (a.k.a. soccer) [1-4].

A pressing behavior of a defending team at each moment can be seen as a combination of multiple instances of pressure relationships [5, 6]. In general, pressing refers to the process in which the defending team aims to pressure the opponent who possesses the ball in order to give him less time to pass and create. The end result should be either forcing the opponent to perform high-complexity technical procedures like long passes, or to force him to lose possession or pass backwards [7].

Advanced pressing is a sub-genre of pressing which aims to perform all the steps above in the final third of the pitch, or as advanced as possible [8]. There are a few reasons for doing this:

- Typically, the opposition's goalkeeper and defenders are the least technical players on the field and most prone to errors [9].

- Winning the ball back in the final third of the pitch allows easy creation of clear cut chances [10].

- Pressing the enemy team up the field renders their main attacking threats (like their attackers, wingers or advanced playmakers) useless since they cannot get the ball [11].

Football history shows us that the concept of advanced pressing is not new. The Dutch national team used it with great success in the 1970s, learning from the experience of their greatest clubs, Ajax and Feyenoord [12-15]. Towards the end of that decade, teams slowly moved from a narrow, deep defense in their own third to a more proactive, higher-up-thepitch pressing. Arrigo Sacchi was one of the pioneers of this system in AC Milan [16].

In modern football, more and more teams are using advanced pressing styles in their tactics - even regardless of what they do with the ball as soon as they recover it [17]. These tactics range from teams which aim to retain possession after winning the ball back (for example, Guardiola's Manchester City or, more generally, Barcelona and other teams who favor possession over attacking moves) to teams which target playing direct football after winning the ball back [18]. Liverpool's Champions League winning run from 2019 is a prime example of using the "gegenpress" style - high intensity pressing and running up the field and aiming to create goal chances immediately after winning the ball back $[19,20]$.

Pressing requires extremely high fitness levels in order to be executed [21]. Players have to be able to close down options for the opposition by applying pressure to the player in possession. It is often hard to execute this style of play for the full 90 minutes without having trained extensively [22].

\section{MATERIAL AND METHODS}

There are some concepts which define advanced pressing:

- Line of engagement. The line of engagement is the imaginary horizontal line behind which the defending team retreats for defending. When an attacker crosses this line with the ball, they are quickly pressed. An extremely high line of engagement is at the level of the opposition keeper, an aggressive one around the central defender line, while a deep one is within the defending team's own half.

- Pressing intensity. This represents the intensity used by the defending players where pressing. This can range from very high (quick adaptations, quick movements, aiming to win the ball even with the price of fouls) to low (slow, mostly to cover angles and put some pressure) 
- Defensive depth. This is a horizontal imaginary line where the deepest outfield players of the defending team sit. A high defensive line means the central defenders are sitting close / at the same level with defensive midfielders, while a deep defensive line has them sitting close to their goalkeeper.

These three concepts merge together in forming 3 types of defensive blocks:

1. A high defensive block is a combination of a high line an engagement and a high defensive line.

2. A medium defensive block is a combination of a medium line of engagement and a medium defensive line.

3. A low defensive block is a combination of a low line of engagement and a deep defensive line.

As observed in most tactical journals, combining a deep defensive line with a high line of engagement makes little sense, since it mostly leaves midfielders very exposed and with a lot of ground to cover [23]. Similarly, a high defensive line with a low line of engagement is very vulnerable to through balls or long passes over the defense.

Advanced pressing is mostly performed by teams using a high defensive block [24]. This defensive block can easily be spotted in teams - it consists of central defenders sitting close to the center of the field, wingers pressing opposition fullbacks and the attacker usually pressing the opposition goalkeeper [25]. Advanced pressing styles usually have two different lines of engagement: either at the level of the opposition goalkeeper (extremely aggressive) or at center-back or fullback level (aggressive).

Also, it is worth mentioning that the degree of success or failure of advance pressing is closely tied with the qualities of the players performing the exercise [26]. From a physical standpoint, players have to have high levels of acceleration and stamina to keep up advanced pressing for an entire game, while they also have to have high values of work rate, tackling and anticipation. Furthermore, the efficiency of advanced pressing also comes from what a team actually accomplishes after winning the ball back - where creativity, decision-making and finishing all come into place.

For the purpose of this article, we have analyzed teams in the English Premier League. We took the data from the site fbref.com [accessed on 20 April, 2021]. We used the viewing method to see the matches in which the English teams are involved. We have analyzed how far up the pitch they usually defend and press, how successful they are with their pressing and what their dependencies are. In recent years, technological advances have allowed the implementation of sophisticated match analysis systems during official sports competitions [27].

The most relevant statistical data is presented in the following table:

Table 1. Pressures in attacking third

\begin{tabular}{lcccccccc} 
& & \multicolumn{7}{c}{ Pressures } \\
\cline { 5 - 9 } Squad & \# PI & 90 s & Press & Succ & $\%$ & Def 3rd & Mid 3rd & Att 3rd \\
\hline Arsenal & 29 & 34 & 4186 & 1201 & 28.7 & 1325 & 1710 & 1151 \\
Aston Villa & 22 & 33 & 4662 & 1263 & 27.1 & 1591 & 1967 & 1104 \\
Brighton & 27 & 34 & 4565 & 1467 & 32.1 & 1518 & 1935 & 1112 \\
Burnley & 24 & 34 & 4153 & 1125 & 27.1 & 1208 & 1859 & 1086 \\
Chelsea & 27 & 34 & 4845 & 1523 & 31.4 & 1546 & 2138 & 1161 \\
Crystal Palace & 22 & 33 & 4797 & 1268 & 26.4 & 1975 & 1986 & 836
\end{tabular}


Pressures

\begin{tabular}{lcccccccc}
\cline { 5 - 9 } Squad & \# PI & 90 s & Press & Succ & $\%$ & Def 3rd & Mid 3rd & Att 3rd \\
\hline Everton & 29 & 33 & 4695 & 1365 & 29.1 & 1888 & 1900 & 907 \\
Fulham & 27 & 34 & 4463 & 1327 & 29.7 & 1528 & 1869 & 1066 \\
Leeds United & 22 & 34 & 5943 & 1772 & 29.8 & 2078 & 2574 & 1291 \\
Leicester City & 27 & 34 & 4497 & 1416 & 31.5 & 1597 & 1929 & 971 \\
Liverpool & 28 & 33 & 4488 & 1454 & 32.4 & 1097 & 1936 & 1455 \\
Manchester City & 23 & 34 & 3976 & 1260 & 31.7 & 980 & 1781 & 1215 \\
Manchester Utd & 25 & 33 & 4264 & 1256 & 29.5 & 1276 & 1859 & 1129 \\
Newcastle Utd & 27 & 34 & 4873 & 1243 & 25.5 & 1874 & 2030 & 969 \\
Sheffield Utd & 25 & 34 & 5495 & 1372 & 25.0 & 1876 & 2340 & 1279 \\
Southampton & 29 & 33 & 4823 & 1512 & 31.3 & 1674 & 2099 & 1050 \\
Tottenham & 24 & 34 & 5166 & 1425 & 27.6 & 1882 & 2267 & 1017 \\
West Brom & 30 & 34 & 4977 & 1378 & 27.7 & 1931 & 2088 & 958 \\
West Ham & 24 & 34 & 4336 & 1173 & 27.1 & 1681 & 1846 & 809 \\
Wolves & 26 & 34 & 4480 & 1357 & 30.3 & 1862 & 1877 & 741 \\
\hline
\end{tabular}

$\mathrm{PI}$ - number of players used in games; $90 \mathrm{~s}$ - minutes played divided by 90 ; Press - number of times applying pressure to opposing player who is receiving, carrying or releasing the ball; Succ - number of times the squad gained possesion withing five seconds of applying pressure; \% - percentage of time the squad gained possesion withing five seconds of applying pressure; Def 3rd - number of times applying pressure to opposing player who is receiving, carrying or releasing the ball, in the defensive 1/3; Mid 3rd - number of times applying pressure to opposing player who is receiving, carrying or releasing the ball, in the middle 1/3; Att 3rd - number of times applying pressure to opposing player who is receiving, carrying or releasing the ball, in the attacking $1 / 3$.

\section{RESULTS}

We can see that usually the teams which press higher up the pitch have better results, although the correlation is not true for all cases. The most successful teams in terms of advanced pressing are:

- Liverpool - 1455 pressing attempts in the final third, with an overall success ratio of $32.4 \%$

- Leeds United - 1291 attempts, overall success ratio of $29.8 \%$

- Sheffield United - 1279 attempts, success rate of $25 \%$

Manchester City, Chelsea, Arsenal, Manchester United and Brighton follow in this regard, all with over 1100 pressing attempts in the final third, after 34 match days in the English Premier League.

We have also analyzed the following table in correlation with the statistics above:

Table 2. Touches in attacking third

\begin{tabular}{lcccccccccc} 
Squad & & & & \multicolumn{7}{c}{ Touches } \\
\cline { 6 - 11 } & \# Pl & Poss & 90 s & Touches & Def Pen & Def 3rd & Mid 3rd & Att 3rd & Att Pen & Live \\
\hline Arsenal & 29 & 53.6 & 34 & 22555 & 2312 & 7495 & 10629 & 5932 & 881 & 21142 \\
Aston Villa & 22 & 48.7 & 33 & 18357 & 2286 & 6063 & 7830 & 5495 & 935 & 16750 \\
Brighton & 27 & 51.5 & 34 & 20949 & 2336 & 7402 & 9110 & 5824 & 925 & 19436 \\
Burnley & 24 & 41.4 & 34 & 17102 & 2065 & 5410 & 8092 & 4459 & 637 & 15592 \\
Chelsea & 27 & 61.3 & 34 & 26504 & 2450 & 8368 & 13002 & 6831 & 965 & 25076 \\
Crystal Palace & 22 & 40.3 & 33 & 17307 & 2019 & 6214 & 8037 & 4101 & 580 & 15769 \\
Everton & 29 & 47.3 & 33 & 20023 & 2556 & 7708 & 9222 & 4351 & 612 & 18640 \\
Fulham & 27 & 49.0 & 34 & 20941 & 2323 & 7241 & 9831 & 5200 & 717 & 19406 \\
Leeds United & 22 & 57.9 & 34 & 22196 & 2742 & 8501 & 9579 & 5526 & 876 & 20582 \\
Leicester City & 27 & 55.0 & 34 & 22549 & 2210 & 7467 & 10870 & 5555 & 761 & 21072
\end{tabular}


Touches

\begin{tabular}{lcccccccccc}
\cline { 6 - 10 } Squad & \# PI & Poss & 90s & Touches & Def Pen & Def 3rd & Mid 3rd & Att 3rd & Att Pen & Live \\
\hline Liverpool & 28 & 62.6 & 33 & 26172 & 1881 & 6830 & 13251 & 7691 & 1155 & 24657 \\
Manchester City & 23 & 64.5 & 34 & 27464 & 1873 & 6296 & 14816 & 8245 & 1243 & 26094 \\
Manchester Utd & 25 & 56.3 & 33 & 23086 & 2016 & 6872 & 10751 & 7062 & 925 & 21624 \\
Newcastle Utd & 27 & 38.7 & 34 & 16741 & 2347 & 6687 & 6870 & 4123 & 561 & 15164 \\
Sheffield Utd & 25 & 41.0 & 34 & 17939 & 2148 & 5884 & 7719 & 5329 & 629 & 16475 \\
Southampton & 29 & 51.9 & 33 & 20221 & 2110 & 6913 & 9973 & 4551 & 681 & 18668 \\
Tottenham & 24 & 51.3 & 34 & 21684 & 2400 & 7400 & 10914 & 4657 & 660 & 20154 \\
West Brom & 30 & 37.7 & 34 & 16489 & 2410 & 6142 & 7135 & 3979 & 571 & 14938 \\
West Ham & 24 & 41.9 & 34 & 18145 & 2189 & 6200 & 8323 & 4727 & 726 & 16662 \\
Wolves & 26 & 48.8 & 34 & 20360 & 2081 & 6756 & 10060 & 4867 & 654 & 18823 \\
\hline
\end{tabular}

$\mathrm{PI}$ - number of players used in games; Poss - possesion; $90 \mathrm{~s}$ - minutes played divided by 90 ; Touches - number of times a player touched the ball; Def Pen - touches in defensive penalty area; Def 3rd - touches in defensive 1/3; Mid 3rd -touches in middle 1/3; Att 3rd - touches in attacking 1/3; Att Pen - touches in penalty area; Live - live-ball touches. Does not include corner kicks, free kicks, throw-ins, kick-offs, goal kicks or penalty kicks.

We can see the same teams (Liverpool, Leeds United, Manchester City, Arsenal, Manchester United and Brighton) leading in terms of touches in the attacking 3rd, with Sheffield United trailing just behind Aston Villa. The same teams lead in terms of touches in the penalty area, as well as expected goals (xG)

Table 3. Spot in expected goals table

\begin{tabular}{|c|c|c|c|c|c|c|c|}
\hline \multirow[b]{2}{*}{ Squad } & \multicolumn{5}{|c|}{ Expected } & \multirow{2}{*}{$G-x G$} & \multirow{2}{*}{$n p: G-x G$} \\
\hline & PK & PKatt & $x G$ & $n p x G$ & $n p x G / S h$ & & \\
\hline Manchester City & 5 & 8 & 66.2 & 60.2 & 0.12 & 3.8 & 4.8 \\
\hline Liverpool & 6 & 6 & 60.8 & 56.3 & 0.11 & -8.8 & -10.3 \\
\hline Chelsea & 7 & 9 & 55.9 & 49.1 & 0.10 & -4.9 & -5.1 \\
\hline Manchester Utd & 8 & 9 & 53.2 & 46.4 & 0.10 & 7.8 & 6.6 \\
\hline Leicester City & 8 & 10 & 50.3 & 42.7 & 0.10 & 6.7 & 6.3 \\
\hline Arsenal & 6 & 6 & 49.3 & 44.8 & 0.11 & -5.3 & -6.8 \\
\hline Leeds United & 3 & 3 & 49.3 & 47.0 & 0.10 & -1.3 & -2.0 \\
\hline Brighton & 6 & 9 & 48.5 & 41.6 & 0.10 & -14.5 & -13.6 \\
\hline Tottenham & 5 & 5 & 47.5 & 43.7 & 0.11 & 11.5 & 10.3 \\
\hline Aston Villa & 4 & 5 & 47.4 & 43.6 & 0.10 & -1.4 & -1.6 \\
\hline West Ham & 2 & 3 & 46.4 & 44.0 & 0.11 & 6.6 & 7.0 \\
\hline Everton & 4 & 4 & 41.0 & 38.1 & 0.12 & 2.0 & 0.9 \\
\hline Fulham & 3 & 6 & 36.8 & 33.1 & 0.09 & -12.8 & -12.1 \\
\hline Wolves & 4 & 4 & 36.1 & 33.1 & 0.08 & -5.1 & -6.1 \\
\hline Southampton & 5 & 6 & 35.3 & 30.8 & 0.09 & 5.7 & 5.2 \\
\hline Burnley & 3 & 3 & 34.8 & 32.5 & 0.10 & -4.8 & -5.5 \\
\hline Newcastle Utd & 4 & 4 & 33.6 & 30.5 & 0.09 & 0.4 & -0.5 \\
\hline West Brom & 4 & 4 & 28.8 & 25.8 & 0.09 & 0.2 & -0.8 \\
\hline Sheffield Utd & 3 & 4 & 27.7 & 24.7 & 0.09 & -10.7 & -10.7 \\
\hline Crystal Palace & 3 & 3 & 25.6 & 23.4 & 0.09 & 6.4 & 5.6 \\
\hline
\end{tabular}

PK - penalty kicks made; Pkatt - penalty kicks attempted; xG - expected goals; npxG - non-penalty expected goals; npxG/Sh - non-penalty expected goals per shot; G-xG - goal minus expected goals; np:G-xG -non penalty goals minus non-penalty expected goals. 


\section{DISCUSSION}

From the above statistics we can see that:

1. There are a fair number of teams who press high up the pitch in the Premier League, and not all of them are considered top teams.

2. From the traditional big 6 teams (Manchester United, Manchester City, Chelsea, Arsenal, Liverpool and Tottenham), Tottenham defends deep, while Manchester United and Arsenal press higher up the pitch, but do not use a high line of engagement.

3. There are other teams which use advanced pressing and are not big clubs, like Leeds United (newly promoted to the Premier League, but famous for their high intensity running and pressing under Marcelo Bielsa), Sheffield United and Brighton.

4. We can see a clear correlation between the success of a team and advanced pressing, depending on the analyzed figures. Depending on the success percentage of their advanced pressing actions, teams enter the final third with the ball a lot more that other teams which do not use advanced pressing. This usually leads to more chances being created and more expected goals. Expected goals are the best way to see if a team creates enough chances from open play. Of course, the system does not guarantee success enough, but it is a good indicator of it. In the graph below (Fig. 1), we have highlighted the teams which use advanced pressing the most in the Premier League and compared their overall league position, xG as well as entries in the last third of the pitch.

Table 4. Premier League position at the end of day 34

\begin{tabular}{|c|c|c|c|c|}
\hline Team & Spot in $\times G$ table & $\begin{array}{l}\text { Progressions in } \\
\text { attacking third }\end{array}$ & High pressing Table & $\begin{array}{c}\text { Premier League } \\
\text { position at the end } \\
\text { of day } 34\end{array}$ \\
\hline Arsenal & 6 & 7 & 6 & 9 \\
\hline Aston Villa & 10 & 4 & 9 & 10 \\
\hline Brighton & 8 & 6 & 8 & 14 \\
\hline Burnley & 16 & 15 & 10 & 16 \\
\hline Chelsea & 3 & 3 & 5 & 4 \\
\hline Crystal Palace & 20 & 18 & 18 & 13 \\
\hline Everton & 12 & 17 & 17 & 8 \\
\hline Fulham & 13 & 11 & 11 & 18 \\
\hline Leeds United & 7 & 8 & 2 & 11 \\
\hline Leicester City & 5 & 9 & 14 & 3 \\
\hline Liverpool & 2 & 2 & 1 & 7 \\
\hline Manchester City & 1 & 1 & 4 & 1 \\
\hline Manchester Utd & 4 & 5 & 7 & 2 \\
\hline Newcastle Utd & 17 & 20 & 15 & 17 \\
\hline Sheffield Utd & 19 & 16 & 3 & 20 \\
\hline Southampton & 15 & 12 & 12 & 15 \\
\hline Tottenham & 9 & 13 & 13 & 6 \\
\hline West Brom & 18 & 19 & 16 & 19 \\
\hline West Ham & 11 & 10 & 19 & 5 \\
\hline Wolves & 14 & 14 & 20 & 12 \\
\hline
\end{tabular}




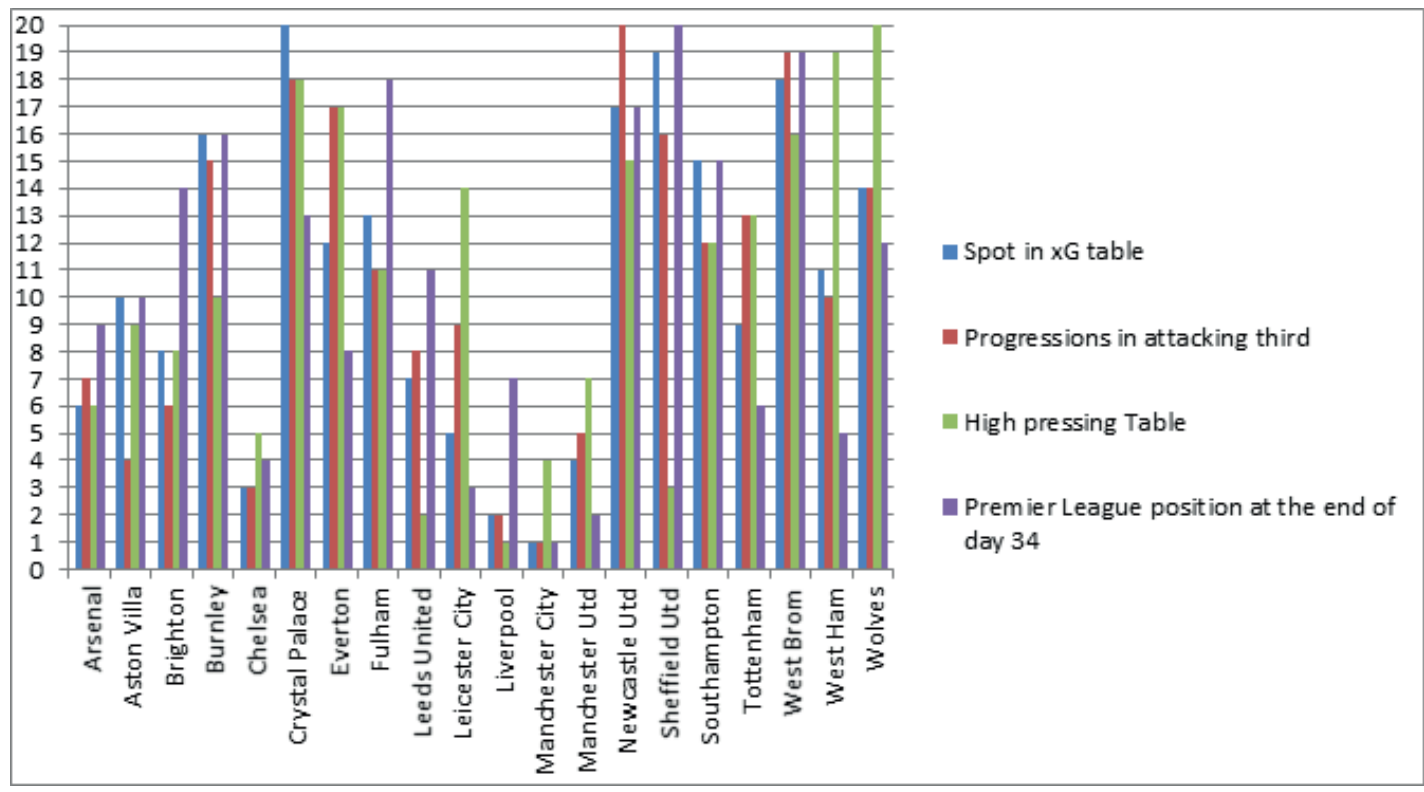

Fig. 1. Comparison between league position, spot in expected goals table, progressions in attacking third and high pressing table

In their work, Bojinov and Bornn, used maps to show the strengths and weaknesses of a team, both in attack and defense. This allows coaches not only to adjust defensive strategy to bolster weak regions, but also to build offensive strategies to exploit an opponent's spatial vulnerabilities [28].

\section{CONCLUSIONS}

Overall, teams which use advanced pressing are more successful than teams which do not use it and defend deep. Advanced pressing produces good results for other attacking statistics as well: entries in the final third, expected goals and overall league position. The $\mathrm{xG}$ table from the previous chapter shows that two of the teams which have implemented advanced pressing are actually low in standings due to other factors like finishing - Brighton and Sheffield United have the biggest negative margin in $\mathrm{xG}$ in the English Premier League. Advanced pressing, though, is not the only success factor. Teams still need to be capable of holding their defensive shape in order to avoid having large gaps between their defenders and their attackers, as well as creating chances and finishing them. Teams with overall weaker players will have a hard time doing something useful with the ball after winning it back. That being said, it is clear that at least in the Premier League, advanced pressing is efficient and produces good results.

\section{REFERENCES}

[1] Andrienko G, Andrienko N, Budziak G, Dykes J, Fuchs G, von Landesberger T, Weber H. Visual analysis of pressure in football. Data Mining and Knowledge Discovery. 2017 Nov;31(6):1793-839. https://doi.org/10.1007/s10618-017-0513-2

[2] Marcu V, Buhaş SD. Sports organizations - management and science. Procedia - Social and Behavioral Sciences. 2014;117:678-682. https://doi.org/10.1016/j.sbspro.2014.02.281

[3] Buhas SD. Sports Management. From Institutionalism to Research. GeoSport Soc. 2015;2(1):26-32.

[4] Andrienko G, Andrienko N, Budziak G, von Landesberger T, Weber H. Exploring pressure in football. In: Proceedings of the 2018 International Conference on Advanced Visual Interfaces 2018 May 29. Castiglione della Pescaia Grosseto Italy, 1-3. https://doi.org/10.1145/3206505.3206558

[5] Buhaș S, Herman GV, Ștef M. Aspects regarding speed development in football game in 12-14-year-old children. GeoSport Soc. 2018;8(1):21-30.

[6] Buhaș SD, Stance L. The Relationship between Personality and Physical Activity. GeoSport Soc. 2017;7(2):72-77.

[7] Dragos P, Lucaciu G, Trifa I, et al. Aspects Regarding the Influence of Communication on the Motivation of Employees in Some Sports Organizations. Proceedings of the 4th International Conference of the Universitaria Consortium 
(ICU 2018): The Impact of Sport and Physical Education Science on Today's Society. Bologna: Editografica S R L; 2018, 73-77.

[8] Slaidiņš K, Fernāte A. Analysis on Classification of Football Technique. Insociety. Integration. Education. Proceedings of the International Scientific Conference. 2021 May 28;4:456-467. https://doi.org/10.17770/sie2021vol4.6439

[9] Seidenschwarz P, Rumo M, Probst L, Schuldt H. A Flexible Approach to Football Analytics: Assessment, Modeling and Implementation. International Symposium on Computer Science in Sport 2019 Jul 8. Cham.: Springer; 2019, 19-27. https://doi.org/10.1007/978-3-030-35048-2_3

[10] Spence J. A comparative analysis of a Category One Academy's U13, U14 and U16 football teams (Doctoral dissertation, University of Chichester)

[11] Kilpatrick D. Inverting the Pyramid: A History of Football Tactics. J Sport Hist. 2011;38(3):530-1.

[12] Marcu V, Buhaș S. Systematic analysis of sports activity. Discobolul. 2011;26(4):35-42.

[13] Dragoș PF, Lucaciu, Dinis, I, Ștef M, Szabo-Alexi P, Buhaș S. Concepts concerning the content of children`s training in some sport games. Proceedings of the 4th international conference of the Universitaria Consortium ( ICU 2018): The impact of sport and physical education science on today`s society. Pianoro, Bologna: Editografica SRL; 2018, 67-72.

[14] Scutti G, Wendt JA. Football and Geopolitics. Geosport for Soc. 2016;5:100-106.

[15] Bo GO. Tendency of Post-modernization in Tactics System of Football [J]. J Tianjin University of Sport. 2007;3.

[16] Bate R. Football chance: tactics and strategy. Science and football; 1988.

[17] Collet C. The possession game? A comparative analysis of ball retention and team success in European and international football, 2007-2010. J Sport Sci. 2013 Jan 1;31(2):123-36. https://doi.org/10.1080/02640414.2012.727455

[18] Ma J. An Analysis of Formation Disruption in Soccer (Doctoral dissertation).

[19] Kijewski T, Wendt JA. Polish Football Teams in the Champions League - Does the Budget Decide Everything? GeoSport Soc. 2019;11(2):101-112.

[20] Robberechts P. Valuing the Art of Pressing. In: Proceedings of the StatsBomb Innovation In Football Conference 2019, 1-11. StatsBomb.

[21] Manolache G, Savu C. Trends and approaches to football tomorrow. Annals of the University Dunarea de Jos of Galati: Fascicle XV: Physical Education \& Sport Management. 2013 Jul;1(2)

[22] Low B, Rein R, Raabe D, Schwab S, Memmert D. The porous high-press? An experimental approach investigating tactical behaviours from two pressing strategies in football. J Sport Sci. 2021 May 14:1-2. https://doi.org/10.1080/ 02640414.2021 .1925424

[23] Stokes JV, Luiselli JK, Reed DD, Fleming RK. Behavioral coaching to improve offensive line pass-blocking skills of high school football athletes. J Appl Behav Analys. 2010 Sep;43(3):463-72. https://doi.org/10.1901/jaba.2010.43-463

[24] Otte FW, Millar SK, Klatt S. How does the modern football goalkeeper train?-An exploration of expert goalkeeper coaches' skill training approaches. J Sport Sci. 2020 Jun 17;38(11-12):1465-73. https://doi.org/10.1080/02640414 .2019 .1643202

[25] Ormenișan S. Study on using pressing in modern football game. Studia Universitatis Babes-Bolyai, Educatio Artis Gymnasticae. 2014 Mar 1;59(1).

[26] Moura FA, Martins LE, Anido RO, Ruffino PR, Barros RM, Cunha SA. A spectral analysis of team dynamics and tactics in Brazilian football. J Sport Sci. 2013 Oct 1;31(14):1568-77. https://doi.org/10.1080/02640414.2013.789920

[27] Dehoorne O, Wendt JA, Mikhailov A, Berdenov Z, Ilies A. Cartographic representation of a sports (football) competition - UEFA Youth League (2013-2019). GeoSport Soc. 2019;11(2):86-100. https://doi.org/10.30892/gss.1104-051. https:// doi.org/10.30892/gss.1104-051

[28] Bojinov I, Bornn L. The pressing game: Optimal defensive disruption in soccer. In: 10th MIT Sloan Sports Analytics Conference; 2016

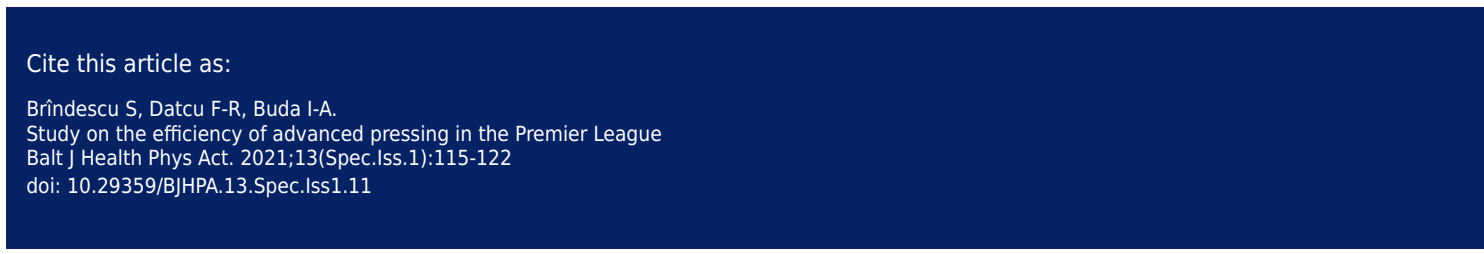

